\title{
The effect of sign language grammatical structure on recall
}

\author{
RYAN D. TWENEY \\ Bowling Green State University, Bowling Green, Ohio 43403 \\ and \\ GARY W. HEIMAN \\ State College of New York at Buffalo, Buffalo, New York 14222
}

\begin{abstract}
The nature of grammatical structure in American Sign Language (ASL) was investigated using a short-term free-recall paradigm. Grammatical signed sentences and random strings of ASL signs were visually presented to 60 deaf ASL users. Either a nonsense sign or a finger-spelled consonant-vowel-consonant (CVC) was embedded in each string. The number of nonsense items recalled and the total number of signs recalled were significantly greater for grammatical strings than for random strings. The results extend previous findings and suggest that, as in speech, grammatical structure is actively utilized in the processing of ASL, serving to increase the efficiency of such processing.
\end{abstract}

Until recently, research in psycholinguistics was confined to spoken languages. As a result, it has not been possible to separate those aspects of human language use which derive from cognitive capabilities and those which derive from constraints imposed by the necessity of auditory reception and vocal articulation. Studies of the psycholinguistic properties of sign languages ${ }^{1}$ are, thus, potentially valuable. Visual reception and manual articulation may impose different channel constraints while utilizing the same cognitive capacities as speech (Jakobson, 1971; Klima, 1975; Stokoe, 1972; Bellugi \& Klima, Note 1). Linguistic analyses of American Sign Language (ASL) indicate that ASL does, in fact, possess linguistic organization comparable to that found in spoken languages. Stokoe (1960), for example, demonstrated the existence of minimal contrasting pairs in ASL, described some aspects of the "phonemic" structure of ASL signs, and provided a written notational system. Later, ASL phonemic structure was shown to predict errors in short-term memory for ASL signs (Bellugi, Klima, \& Siple, 1975), just as acoustic parameters predict errors in memory for spoken words (Conrad, 1972).

It has also become clear that ASL possesses intersign grammatical structure as complex as that found in

This research was supported in part by National Institutes of Health Research Grant NS-09590-03 from the National Institute of Neurological Diseases and Stroke, Harry W. Hoemann, Principal Investigator. We are grateful to Horace Reynolds, Chairman, Department of Psychology, Gallaudet College, and to Clarence Williams, Associate Dean for Research, Gallaudet College, for their assistance in obtaining subjects and physical facilities. spoken languages, though very different in structure (Stokoe, 1972; Woodward, 1973; Bellugi \& Klima, Note 1; Liddell, Note 2). The presence of grammatical structure has been shown to have important psycholinguistic implications for production and understanding in speech. Thus, such structure greatly facilitates performance in laboratory tasks involving speech (e.g., Brent, 1969; Miller \& Isard, 1963; O'Connell, 1970). To determine whether the same was true for ASL, Tweney, Heiman, and Hoemann (in press) investigated performance of deaf subjects in a perceptual task. Grammatical ASL sentences, semantically anomalous ASL strings, and lists of random strings were used as stimuli. Each set of items was presented on video tape to 24 profoundly deaf college students who were fluent ASL users. Presentation was disrupted by use of a temporal interruption circuit which blanked the video screen twice per second, leaving the screen on for $50 \%$ of the total time. Subjects reported as much of each sentence as they could. Significantly more signs were reported in grammatical strings than in either anomalous or random strings. The same trends were found in a short-term memory task using similar stimuli, but without video disruption. The results suggest that the grammatical structure of ASL is "psychologically real" (Fodor, Bever, \& Garrett, 1974) and facilitates performance in the same way that English grammatical structure facilitates performance with auditory stimuli. Since the devices by which ASL achieves grammaticality are so different from those utilized by spoken languages, however, the result also implies that the capacity to understand and use linguistic structure has little to do with specific input or output channels. In particular, the sequential properties of speech may, 
indeed, reflect properties of the input channel rather than limitations of the cognitive mechanisms.

This argument would not be compelling, however, if the effects of ASL structure were relatively weak. If ASL grammatical structure was involved in only a peripheral fashion (if, say, it served only to provide a familiar overlearned framework upon which a subject reconstructed partially perceived or remembered stimuli), then the parallel between speech and ASL would be seriously weakened. In the presence of disruptive visual noise, such as that used by Tweney et al. (in press), the search for structure is both active and demanding. The presence of familiar grammatical sequences may make such structure easier to find. The results do not, therefore, rule out the possibility that grammatical structure is unimportant in ordinary ASL processing, though useful as a mnemonic aid in difficult tasks.

The present study was conducted to test this possibility. A short-term free-recall task was used in which nonsense gestures were included in either grammatically or randomly arranged strings of signs. If grammatical structure does, in fact, facilitate encoding of a sequence of signs, then recall of the nonsense gestures should be facilitated as well as recall for the grammatical strings themselves. A similar result has been demonstrated repeatedly for English strings (O'Connell, 1970). If ASL syntax merely serves to provide a familiar matrix around which recall can be structured, then recall for nonsense gestures should not be affected, since they represent unfamiliar items. Such an outcome would suggest that ASL structure is relatively peripheral and would weaken the analogy between sign and spoken grammatical structure.

\section{METHOD}

\section{Subjects}

Sixty deaf students (mean age $=23.5$ years) at Gallaudet College in Washington, D.C., served as subjects and were paid for participating. Gallaudet is a residential college for profoundly deaf and hard-of-hearing students. All classes are conducted in either English and sign or in sign alone. ASL is widely used on the campus. All subjects were profoundly deaf, and all were either congenitally deaf or had become deaf prior to age 3 years. According to subjects' self-reports, mean number of years of ASL use was 15.3.

\section{Stimulus Materials}

Twenty-five five-sign grammatical ASL sentences were randomly selected from a set of 200 sentences constructed by two deaf informants. Only signs in common use at Gallaudet were used. All selected sentences were considered natural, grammatical, and semantically interpretable by native users of ASL. A second set of randomly assigned five-sign strings was constructed by permuting the 125 signs of the grammatical sentences and then eliminating strings which contained grammatical subsequences.

Twenty-five nonsense signs were constructed by an informant in accord with the formational constraints of ASL signs. Twentyfive consonant-vowel-consonants (CVCs) with Glaze association values of $20 \%$ (Hilgard, 1951) were also selected. Nonsense signs were formed by unitary gestures, while CVCs were finger spelled using one conventional letter-hand gesture for each letter. Stimulus lists were prepared by systematically replacing one sign from each sentence with either a nonsense sign or a fingerspelled CVC. This was done for both grammatical and random strings. Table 1 gives the complete set of grammatical sentences with the CVC replacement. The nonsense sign list was identical, except that nonsense signs instead of CVCs were used.

Each list was signed at a constant rate by a deaf female assistant and was videotaped. Normal ASL facial expression and lip movements accompanied all signing, except that nonsense signs and CVCs were signed "dead pan." Normal ASL sentence intonation was used with all strings.

\section{Procedure}

Fifteen subjects were randomly assigned to each of the four lists. Two orders of each list were used. Following each string, subjects were instructed to recall as much as they could. Signed responses were videotaped and scored by two naive deaf informants, who agreed on more than $90 \%$ of all responses.

\section{RESULTS AND DISCUSSION}

The mean number of signs recalled in each condition is shown in Table 2 . The ASL strings were clearly easier than the random strings $(\mathrm{F}=16.45, \mathrm{df}=1 / 56, \mathrm{p}<.001)$, whereas there was no effect due to the difference between nonsense signs or CVCs $(F=.429, \mathrm{df}=1 / 56$, $\mathrm{p}>.05$ ), and no interaction between the two factors $(F=.771, \mathrm{df}=1 / 56, \mathrm{p}>.05)$. Table 2 also presents the mean proportion correct of the nonsense items. Here, also, there was a significant difference between gram-

Table 1

Stimulus Materials

1. MEF (ask) teacher excuse from class.

2. ZUD (hate) movies talk too much.

3. TEV (need) new shoes for church.

4. JEX (stay) home for me tonight?

5. PUY (good) looks will interest many.

6. That FEP (girl) don't want study.

7. Look KEB (out) some snakes bite.

8. Give NOJ (me) your red handkerchief.

9. Enjoy BUW (listen) your long conversation.

10. Reserve TAH (seat) for me please.

11. Read comics BEW (make) me relax.

12. Left my VAB (jacket) your dorm.

13. Let us WUX (watch) game ourselves.

14. My secret FUB (not) tell you.

15. Want go HAJ (airport) with me.

16. Cop want your ZAN (driver) license.

17. Build my home YOL (with) wood.

18. That boy voice HIF (like) woman.

19. Your wedding ring NIJ (very) pretty.

20. Draw two pictures YEM (for) me.

21. Promise me will see JAT (you).

22. Smart person not always LIJ (perfect).

23. Bird sing near my TEF (window).

24. Write short story not PAF (easy).

25. Don't ask me many BIW (questions).

Note-Each word is an English gloss of an ASL sign of roughly equivalent meaning. CVC replacements are indicated in uppercase letters, and the sign which was replaced is indicated in parentheses. 
Table 2

Results of Recall Task

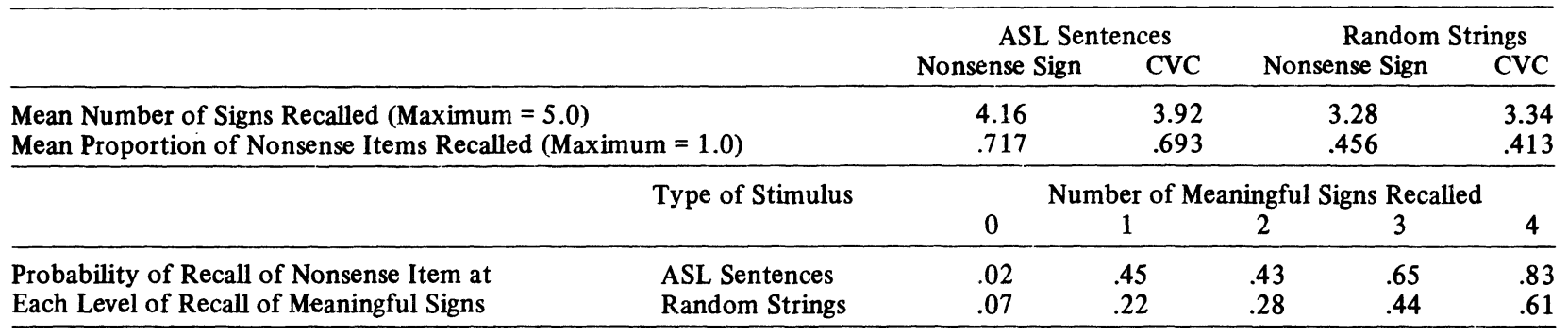

matical and random strings $(F=23.72, \mathrm{df}=1 / 56$, $p<.001)$ but no effect due to type of nonsense item $(F=.264, \mathrm{df}=1 / 56, \mathrm{p}>.05)$ or to the interaction $(F=.015, d f=1 / 56, p>.05)$. The results support the hypothesis that presence of ASL structure contributes to ease of processing.

If ASL structure does, in fact, facilitate processing of nonsense items, then it should be easier to recall a nonsense item for a given number of recalled signs from grammatical sequences than for the same number of recalled signs from random strings. In other words, the conditional probability of recall of a nonsense item, given that $\mathrm{N}$ other items have been recalled, should be greater for ASL sentences than for random strings, for all values of $\mathrm{N}$. When $\mathrm{N}$ is zero, however, there should be no difference in recall of the nonsense items. The appropriate data, shown in Table 2, confirm the expected relationships. It is clear that the facilitative effect of ASL grammatical structure is due to the increased efficiency in processing which such structure provides.

The findings of the present study, thus, confirm the previous findings of Tweney et al. (in press) and rule out the possibility that the earlier results are due to relatively peripheral mechanisms. The specific mechanisms by which ASL facilitates processing are not, of course, illuminated by this study or by the earlier one. Nevertheless, it now appears clear that syntactic processes in ASL are "abstract" in a way which is independent of particular input or output channels. More generally, grammatical structure appears to derive from human cognitive capabilities, rather than from specific characteristics of an input or output channel. This conclusion, we believe, substantially extends the scope of current psycholinguistic theory and opens many possibilities for new empirical investigations.

\section{REFERENCE NOTES}

1. Bellugi, U., \& Klima, E. S. Two faces of sign: Iconic and abstract. Paper presented at the Conference on Origins and Evolution of Language and Speech, New York Academy of Sciences, New York, New York, September 1975.

2. Liddell, S. Restrictive relative clauses in American Sign
Language. Unpublished manuscript, The Salk Institute, La Jolla, California, 1976.

\section{REFERENCES}

Bellugi, U., Klima, E. S., \& Siple, P. Remembering in signs. Cognition: International Journal of Cognitive Psychology, 1975, 3, 93-125.

BRENT, S. B. Linguistic unity, list length, and rate of presentation in serial anticipation learning. Journal of Verbal Learning and Verbal Behavior, 1969, 8, 70-79.

ConRAD, R. Speech and reading. In J. F. Kavanagh \& I. G. Mattingly (Eds.), Language by ear and by eye: The relationships between speech and reading. Cambridge, Mass: MIT Press, 1972.

Fodor, J. A., Bever, T. G., \& GarretT, M. F. The psychology of language: An introduction to psycholinguistics and generative grammar. New York: McGraw-Hill, 1974.

HilgaRD, E. R. Methods and procedures in the study of learning. In S. S. Stevens (Ed.), Handbook of experimental psychology. New York: Wiley, 1951.

JAKOBSON, R. About the relation between visual and auditory signs. In R. Jakobson (Ed.), Selected writings II: Word and language. The Hague: Mouton, 1971.

Klima, E. S. Sound and its absence in the linguistic symbol. In J. Kavanagh \& J. Cutting (Eds.), The role of speech in language. Cambridge, Mass: MIT Press, 1975.

Miller, G. A., \& Is ARD, S. Some perceptual consequences of linguistic rules. Journal of Verbal Learning and Verbal Behavior, 1963, 2, 217-223.

O'Connel, D. C. Facilitation of recall by linguistic structure in nonsense strings. Psychological Bulletin, 1970, 74, 441-452.

Stokoe, W. C., JR. Sign language structure, an outline of the visual communications system of the American deaf. Studies in Linguistics, Occasional Paper No. 8, Buffalo, New York, 1960.

Stокое, W. C., JR. Semiotics and human sign languages. The Hague: Mouton, 1972.

Tweney, R. D., Heiman, G. W., \& Hoemann, H. W. Psychological processing of sign language: The effects of visual disruption on sign intelligibility. Journal of Experimental Psychology: General, in press.

WoodwARD, J. C., JR. Inter-rule implication in American Sign Language. Sign Language Studies, 1973, No. 3, 47-56.

\section{NOTE}

1. Sign languages are gestural communication systems which encode meanings by relating them to unitary gestures in a regular way. They must be distinguished from finger-spelled versions of spoken languages, which are similar to an orthography rather than to a true sign language. In the United States, 
the most widely used manual language is American Sign Language (ASL). It must be distinguished from Signed English, which consists of a sequence of true signs in English grammatical order, sometimes with finger-spelled English function words. Grammatical order in ASL is often quite different from that of English, and ASL uses modulational and inflectional devices (e.g., shifts in sign locus to indicate tense) wholly unlike those of either speech or Signed English.

(Received for publication June 22, 1977.) 